\title{
ENSINO DE PORTUGUÊS PARA FALANTES DE OUTRAS LÍNGUAS: IDENTIDADES E [RE]INVENÇÕES EM CONTEXTO DE INTEGRAÇÃO
}

\author{
Jocenilson Ribeiro*
}

RESUMO: O objetivo deste artigo é descrever e analisar uma experiência didática com o ensino de português para não brasileiros na UNILA pontuando os desafios teóricos e didáticos em um contexto intercultural e plurilíngue. Para melhor visualização dessa análise, me reporto exclusivamente a uma turma (português - nível básico) constituída por 15 estudantes hispanofalantes oriundos de cinco nacionalidades, sobre a qual sintetizo alguns aspectos interculturais para pensar o problema da identidade e das representações no ensino de português para falantes de outras línguas ou como língua não materna. Para tanto, discuto a pertinência de algumas designações, a exemplo de língua adicional, para a especificidade do português ensinado e aprendido no contexto de imersão, transfronteiriço e de integração por onde os sujeitos transitam.

PALAVRAS-CHAVE: Ensino de PFOL; Identidade; Língua-Cultura; Representações; UNILA.

\section{Introdução}

Como um discurso de possibilidade, a linguagem deve ser compreendida tanto como uma política da representação quanto como uma prática social através da qual identidades são reconfiguradas, lutas são produzidas e esperanças mobilizadas. (GIROUX, 1995, p. 96)

Em depoimento dado ao jornal curitibano Gazeta do Povo, numa reportagem especial de 18 de setembro de 2014 a respeito da experiência de aprendizagem de português como língua não materna, uma francesa, estudante de jornalismo à época, relata como aprendeu a língua e como se sente ao adquirir fluência. Entre questões como dificuldades de compreensão de piadas e brincadeiras ou pronúncias e sotaques, ela afirma o seguinte:

Eu penso que, quando as pessoas falam outra língua, sempre parecem muito fofas e simpáticas, além de um pouco tontas. Agora, que eu sei falar mais fluentemente, eu posso exprimir todos os sentimentos que tenho. E, para mim, essa era a parte mais frustrante do

* Doutor em Linguística pela Universidade Federal de São Carlos (UFSCar). Realizou estágio doutoral em Paris pela Université Sorbonne Nouvelle-Paris 3 sob orientação do Prof. Dr. Christian Puech entre 2012 e 2013. Professor Adjunto da Universidade Federal de Sergipe (UFS). 
aprendizado da língua: não poder mostrar quem eu era "na vida real". (MOROTTA, 2014, s.p., grifo meu)

A citação da francesa nos revela o que toda língua cumpre como função, isto é, mostrar aquilo que somos "na vida real", com todas as suas aspas, e "na ficção", eu acrescentaria. Por um lado, a língua é um objeto humano de natureza semiótica da ordem da expressão das identidades, daquilo que somos na vida; porém, por ser da ordem da linguagem, como qualquer outra língua, ela mostra aquilo que somos nas esferas ética e estética (BAKHTIN, 1997), e na superfície das representações, porque não há outro modo de exprimir nossos sentimentos e nos revelar fora da linguagem. É nesse ponto que as aspas da estudante francesa parecem fundamentais no seu enunciado posto que, como linguagem, a língua não cumpre outro papel senão a de representação de nossas identidades. Ela produz nossas identidades.

O que venho trazer aqui é exatamente esse tipo de reflexão. Como recorte, trago minha própria experiência de docente-pesquisador no campo teórico dos estudos do discurso e no campo didático-pedagógico na Universidade Federal da Integração Latino-Americana (UNILA) ${ }^{1}$ do primeiro semestre de 2016 até fins de 2019, trabalhando com estudantes de várias nacionalidades, além da brasileira. Nesse texto, propositalmente, não separarei de forma tão marcada o limite entre a experiência teórica e a experiência didática, tendo em vista exatamente essa relação que me fará refletir as identidades que acabamos assumindo [in]conscientemente quando ocupamos diferentes lugares na Universidades: o lugar de docente, o de pesquisador, o do gestor, o de professor de português para estrangeiro e/ou falantes de outras línguas, o de falante/aprendente de outras línguas, o de escuta dos estudantes em suas línguas maternas... enfim, o lugar do docente que precisa se deslocar, muitas vezes, para uma das extremidades da sala, permitindo o protagonismo dos aprendentes- 
falantes com suas histórias ao revelar em cada encontro quem eles são "na vida real" em contato com essa outra-nova língua. Tal experiência ao longo do tempo me trouxe duas "conclusões filosóficas" (e assumo o paradoxo que me impõe essa expressão): (1) há estrangeiro[a]s tão brasileiros[a]s na semiologia da língua portuguesa que quase ninguém percebe sua outra identidade linguística; (2) há brasileiros[a]s tão estrangeiro[a]s na semiologia da cultura do outro, que suas identidades se intercambiam para além das fronteiras. Os professores de línguas devem[os] estar conscientes dessas possibilidades de trânsito intercultural.

Partindo de uma reflexão sobre o trabalho do professor de Português para Falantes de Outras Línguas (PFOL) e como Língua Não Materna (PLNM), o objetivo desse artigo é descrever e refletir [sobre] minha experiência com o ensino de português para sujeitos não brasileiros na UNILA tentando revelar os desafios teórico-metodológicos e didáticos em um contexto intercultural e plurilíngue. Para melhor visualização dessa análise, me reporto exclusivamente a uma única turma (português - nível básico) constituída por 15 estudantes hispanofalantes oriundos de cinco nacionalidades.

Esse artigo está dividido em 3 seções: na primeira, procuro problematizar o movediço campo do ensino de português para falantes de outras línguas procurando situar o objeto lingua a partir de três noções interdependentes, para as quais o lugar do professor e dos aprendentes está interligado pela língua-cultura (MENDES, 2011, 2015), produzindo identidades. Na segunda seção, apresento como recorte alguns acontecimentos discursivos durante um curso, cuja turma descrevo como síntese do deslocamento identitário provocado pela relação professor-estudantes em um espaço de enunciação plurilíngue e intercultural. Finalmente, na terceira seção apresento algumas observações no universo da prática e concentro-me na questão da representação como noção vinculada ao tema das identidades no processo de ensino-aprendizagem e aquisição do português na UNILA.

\section{Português como língua não materna: reflexões a partir de experiências em curso}

Antes de partir para questões mais específicas relacionadas ao ensino de língua portuguesa, em particular de língua portuguesa para falantes de outras línguas, é preciso nos lembrar 
de algumas questões que nos parecem essenciais. Estas questões devem ser feitas aqui não com o intuito de chegar a respostas inquestionáveis, porque não é este o propósito, mas para entender nosso contexto e nossa prática. Sabemos, pois, que as questões a seguir têm se constituído como problema de investigação da área de ensino de L2/LE. A primeira delas é a seguinte: falar de PFOL é o mesmo que falar de PLNM e de PLE? A segunda: essas acepções caminham na mesma direção quando partimos para as primeiras reflexões ao preparar aulas ou planejar um curso de língua portuguesa e quando o sujeito da aprendizagem não teve (ou não tem) as mesmas experiências históricas, interculturais, educacionais ao longo de sua vida familiar e escolar no Brasil ou no núcleo familiar brasileiro? A terceira: em que medida se confundem e se separam o objeto teórico (OT), o objeto pedagógico (OP) e o objetivo semiótico (OS) no ensino de português tanto para o professor quanto para o aprendente?

Embora venha aqui apresentar esta divisão conceitual e metodológica a partir de minha própria reflexão, o que esquematizo a seguir, gostaria de registrar que esse tipo de questionamento me surge a partir da leitura do trabalho "ILA - ILF - ILE - ILG: Quem dá conta?”, da professora Clarissa Menezes Jordão (2014), no qual “discute pressupostos e implicações dos termos lingua franca, internacional, global, estrangeira e adicional relacionados ao inglês" (JORDÃO, 2014, p. 13, grifo da autora). A pesquisadora não faz essa divisão, isso não faz parte de seus objetivos. Mas suas reflexões me conduzem a pensar no modo como concebemos a língua não materna que ensinamos e as implicações de sua nomeação, já que isso está diretamente relacionado à concepção de "objeto-língua" que adotamos desde a preparação da aula, passando pela uso-ensino em sala e a avaliação do uso-aprendizado e produção-compreensão pelos não brasileiros.

Em síntese, aclaro que a noção de português como língua não materna, conforme o esquema representado na Figura 1, é objeto teórico (episteme) à medida que transformamos esse objeto em conceito, elemento nomeável e decifrável na academia, nos congressos e na ciência como um todo, no discurso científico, na condição de objeto de estudo metalinguístico e como problema de investigação, abordagem metodológica e compreensão filosófica. É objeto didático (práxis) quando o transformamos em ação e reflexão de nossas 
práticas; ao o visualizarmos como um fim do processo pedagógico de uma aula qualquer, com um objetivo bem claro para o processo de ensino-aprendizagem numa dada aula, num dado curso, numa etapa demarcada na sequência didática, vislumbrando habilidades e competências de sujeitos dentro de um programa construído previamente. Por fim, é objeto semiótico (signum) no momento em que passa a fazer parte do uso e da vida do estudante, de suas práticas discursivas e sociais, da interação com o outro; quando subjetiva aprendente como falante de português brasileiro na cultura, como estrangeiro que aprendeu português depois de sua[s] língua[s] materna[s] ou de uma L2 anterior, como lusófono, como filho de lusófonos, como haitiano que aprendeu português, como alguém que "se defende" ou "se camufla" na língua, como se fosse um nascido numa comunidade de falante caboverdiana, angolana, portuguesa ou carioca, nordestina ou sulista no interior do próprio Brasil.

Figura 1: PFOL como objetos de aquisição e ensino-aprendizagem

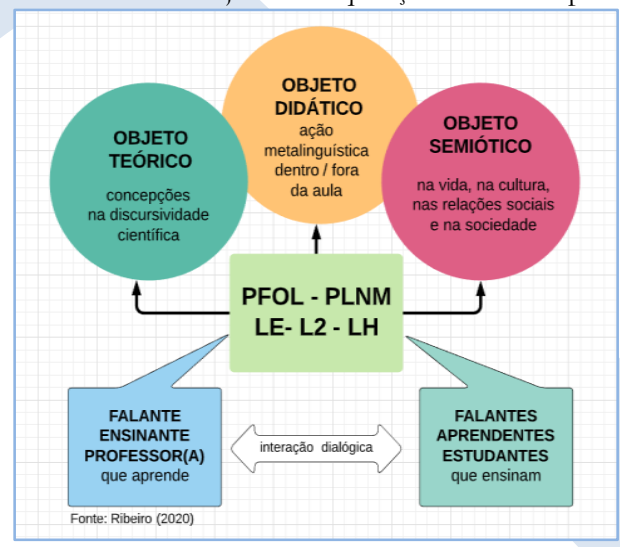

Nessa concepção de língua, evito associá-la à noção de comunicação. Percebo que esse conceito de língua é ainda recorrente no discurso de alguns linguistas aplicados sobretudo aqueles que mantêm em seu campo semântico de atuação investigativa e pedagógica o conceito de competência comunicativa - conceito-chave da "abordagem comunicativa" (cf. HYMES, 1972. WIDDOWSON, 1978. CANALE; SWAIN, 1980. ALMEIDA FILHO, 1993.) adotada no âmbito do ensino de línguas estrangeiras no decorrer das décadas de 
1980 e 1990. Evidentemente, no interior dessa concepção, há uma crítica salutar que muito tem contribuído para nossa atuação como professores de línguas estrangeiras no Brasil. Todavia, evito essa concepção comunicativa, mesmo ciente do amplo espectro do conceito, porque concebo a língua PFOL para além de uma mera instrumentalidade comunicativa e/ou cultural. Toda e qualquer língua carrega um conjunto de significados, incluindo aqueles construídos em processos comunicativos; uma língua se constitui como espessura histórica de cada sociedade e se apresenta como um inventário sociocultural de um povo e de seus falantes através do qual estes falantes (natos e aprendentes) se subjetivam, compartilham saberes, sedimentam psíquica e corporalmente os sentidos que lhes atravessam no tempo, na sociedade e nas relações sociais. Nesse sentido, o professor aprende com os estudantes que ensinam a seus numa constante relação dialógica que se dá na interação.

Vista por esse viés, a língua é objeto semiótico para além de sua funcionalidade comunicativa, porque mesmo no silêncio, mesmo sem comunicar algo no sentido clássico e operacional do termo, ela é constitutiva da identidade dos sujeitos como expressão de poder e de resistência (FOUCAULT, 1995; 1996; 2001) porque não há relações de poder na língua e entre seus falantes sem resistências. O poder então não é algo que detém o sujeito falante (ou o aprendente dessa língua) como bem discute Severo (2013) à luz das ideias foucaultianas; ao contrário, o poder se constitui como efeito dessa língua subjetivando tanto seu falante fluente quanto seu aprendente. Dessa maneira, a língua portuguesa, na sua diversidade, em contexto plurilinguístico sobretudo e como objeto didático, se constitui na sala de aula (e fora dela) como objeto simbólico metalinguístico em disputa de [entre]lugar com outras línguas, com as línguas que fazem parte da vida dos sujeitos. Nessa entoada, incluo também as disputadas de posições sociodialetais no interior dessa variante brasileira, bem como as demais variedades a exemplo da angolana, da portuguesa, da moçambicana, da timorense etc.

Parece-me que tecer uma reflexão com o objetivo de fazer pensar nossas concepções de língua portuguesa não materna é um caminho salutar, tendo em vista que, para muitos professores bem como para o próprio estudante, estas nuances são bem tênues, quiçá signifiquem a mesma coisa, mas sua diferenciação diz respeito também ao modo 
como conduzimos nossa prática. Ou melhor, diz respeito ao modo como nós concebemos a língua na prática porque nós somos sujeitos de interação, de construção e de identidades fluidas na assunção de papéis em sala de aula.

O lugar do professor e do aluno, na visão clássica dessas posições, parece muito claro. Afinal quem não difere um professor de um aluno numa aula de língua? Contudo, o lugar do professor falante e mediador numa sala de aula convencional transita numa posição fluida (i) quando o aluno é pensado num coletivo (os estudantes de língua portuguesa) e sujeito de uma ação (interação e aprendizagem); (ii) quando o professor traz consigo uma concepção de historicidade - se percebe a diferença com o outro marcada pelas experiências singulares de cada país e grupo cultural; (iii) quando a aula é planejada visualizando a relação problema-resposta - a partir das questões que o professor almeja para além do jogo pergunta-resposta, do material didático eleito (autêntico ou não) e de como os próprios estudantes expõem, respondem ou não o que se planejou; e, por fim, (iv) quando se reflete através da avaliação - os resultados que aluno e professor trazem ao final do processo de ensino-aprendizagem-interação. Nesse sentido, concluímos que há um problema de identidade e de representação (HALL, 2000, 2016; SILVA, 2000) de lugares que desestabilizam o espaço do professor e do aluno, pois aluno aprende, apreende, questiona, responde, ensina; o professor ensina, provoca-o a pensar na língua, responde, questiona e aprende; e o material didático "circula" - ora no centro da sala como alvo ou válvula que desencadeia conflitos, ora no silêncio do processo didático como abandono.

Dito isso, devemos voltar às questões que pontuei no início desta seção. $\mathrm{O}$ ponto de partida pode se apresentar da seguinte forma: o português para falantes de outras línguas ou como língua não materna é concebido como OT e OD, visando seu domínio como OS para aqueles que ainda não a dominam com certa fluidez (ou aos que não se reconhecem nela, mesmo que a falem ou a entendam), para os sujeitos que não se subjetivam nessa língua nem subjetivam seus interlocutores, tampouco representam o mundo, suas narrativas e suas vidas nela. O segundo ponto diz respeito ao modo como o professor concebe a língua na sua prática e ao modo como o[a] aprendente a assume durante sua experiência linguística em sala de aula e fora dela. Dito de outro modo, isso significa que o[a] estudante 
de português pode assumir a língua como OD (na sala de aula, durante o processo de ensino-aprendizagem) e OS de modo muito diferente e diferente também nas relações interacionais entre seus colegas no uso da língua. Há aí um problema vinculado à maneira como os sujeitos dessa língua se relacionam com ela, com o[a] professor[a] e com seus colegas de turma.

Para pensar melhor o que acabo de discutir, trago aqui um acontecimento vivenciado numa situação de aula, de prática de ensino, a partir da experiência de um curso que descreverei na próxima seção.

Numa aula de leitura, na nona semana do semestre ${ }^{2}$, que vou chamar de Aula 16, acabávamos de conhecer o site da Plataforma do Letramento ${ }^{3}$, projetado na parede da sala, quando pudemos percorrer as páginas do portal, clicar em alguns botões, identificar os tipos de imagens, reconhecer personalidades indígenas, professores e pesquisadores nacionais ou estrangeiros, analisar a estética do site e os textos verbais e não verbais que compunham a totalidade da tela. Além disso, solicitei aos estudantes, num primeiro momento, que escolhessem algumas palavras, imagens ou conceitos a partir dos quais pudéssemos estabelecer uma compreensão mais holística da discursividade da página que, na sequência, deveriam ler.

No meu planejamento, havia definido a reportagem de Mônica Cardoso "A língua nas margens: multilinguismo e letramento indigena " como segunda etapa desse processo de leitura em língua portuguesa. Notei então três tipos de posturas dos 15 estudantes diante da análise da Plataforma do Letramento: (a) o grupo dos que não elegeram nenhuma palavra/con-

\footnotetext{
2 Segundo calendário oficial da UNILA, do semestre letivo de 2017, o programa de curso era dividido em 18 semanas e 36 encontros. A $9^{\text {a }}$ semana ( 3 e 5 de maio) correspondeu exatamente à metade do curso quando os estudantes estrangeiros já levavam cerca de 60 a 70 dias de vivência acadêmica internacional, de integração com outros estrangeiros e brasileiros dentro e fora da Universidade, de vivência da/na língua portuguesa em diversas esferas sociais de uso (banco, supermercado, bibliotecas, consulados e secretaria da Polícia Federal para, por exemplo, regularização de passaporte, renovação de visto ou retirada da Carteira de Registro Nacional Migratório (CRNM) etc.

${ }^{3}$ Disponível em: <http://www.plataformadoletramento.org.br/>. Acesso em: 15 abr. 2020.

${ }^{4}$ Disponível em: < http://www.plataformadoletramento.org.br/alfabetizacao-indigena/>. Acesso em: 15 abr. 2020.
} 
ceito, foram indiferentes, inexpressivos ou não apresentaram nenhuma atitude eufórica/disfórica a partir da orientação que havia deixado por escrito no quadro negro; (b) o grupo dos que, ao contrário do anterior, reagiram de forma eufórica ou entusiasmada, selecionaram palavras e fotografias para discutir, relacionando-as com o que sabiam ou conheciam (nesse grupo, os paraguaios e alguns colombianos se destacaram); e, por fim, (c) o grupo formado por um peruano e uma chilena sentados em posições equidistantes na sala; ambos provocaram uma discussão em desacordo com a importância do tema e daquela leitura. $\mathrm{O}$ estudante peruano dizia não entender nada da plataforma porque nada tinha a ver com a sua área de formação, a biologia, e, por isso, não escolheu nenhuma palavra, imagem ou conceito. Já a estudante chilena disse não querer seguir a leitura porque não tinha interesse em questões das línguas indígenas ou outro problema relacionado aos povos originários; logo, aquela atividade lhe parecia “aburrida” (entediante), talvez se interessasse mais por um tema de gramática, o que para ela tinha mais a ver com a aula.

Esse tipo de manifestação, como era de se esperar, produziu um efeito a partir de um debate acalorado, no qual o português (língua não materna) sai de cena e o espanhol (língua materna) passa a dominar a sala como se fosse uma forte discussão em assembleia. Parecia que pouco se entendia entre eles ainda que fosse língua "nativa" de todos. O que estava em jogo, a meu ver, atravessava aquilo que é da ordem das identidades, recuperando discursos cuja memória da disputa simbólica entre língua (e cultura) de prestígio e línguacultura sem prestígio estava latente nos enunciados a propósito dos povos originários.

$\mathrm{Na}$ condição de professor, gerenciar as disputas de vozes, o direito do turno de fala, e transformar tal conflito em um debate didático e metalinguístico, fazendo-os voltar à reportagem, era um desafio para mim cercado de tantos outros. O desafio da limitação da língua portuguesa ainda no nível básico - embora alguns já apresentassem um bom desempenho (cf. Quadro 01 na seção seguinte) - diante de um desentendimento que lhes exigia competências linguísticas argumentativas e significados mais profundos que apenas sua língua materna lhes possibilitava; o desafio de articular a noção de "multilinguismo" do texto de Mônica Cardoso com a ação pedagógica num grupo de sujeito que, por sua própria natureza, já era marcado pelo plurilinguismo e, finalmente, o desafio de trabalhar a leitura 
quando o que se lê desestabiliza todos os sujeitos da aula de PFOL. O que se lê, numa situação dessa, não é apenas da ordem do texto e da língua, mas dos discursos que giram em torno das identidades, das posições de [des]prestígio que algumas delas ocupam na história dos povos latino-americanos.

Quero concluir este ponto recuperando a questão que desenvolvia há pouco a propósito da relação que os sujeitos estabelecem com as línguas e com a língua que se está aprendendo. Cada sujeito se relaciona com a língua não materna no processo de aprendizagem ou de aquisição de modo diferente, com interesse, afeto ou indiferença. Tal diferença tem a ver com o conjunto de valores e significados que ele carrega daquela língua-cultura, bem como o papel que a língua assume na sociedade da qual ela faz parte, além de como ele se envolve nessa língua-cultura. Então, ainda que, em um grupo de estudantes de português, esteja presente uma língua materna que os "unifique" como hispanofalantes em um contexto universitário, integracionista, brasileiro e fronteiriço, estes falantes são marcados por inúmeras diferenças que definem suas identidades não para homogeneizar, mas para singularizar a sua relação com a língua portuguesa. É nesse sentido que a noção de PFOL, ainda que abrangente, dá melhor conta do contexto que venho descrevendo do que a noção de português como lingua adicional tal como vem sendo adotada na UNILA, posto que esta última noção não contempla a complexidade e a heterogênea realidade da sala de aula e fora dela quando me refiro ao contexto daquela universidade.

A denominação Língua Adicional (LA), conforme apresentada por Schlatter e Garcez (2009), ainda que venha sendo adotada no Brasil para diversas situações e contextos de ensino-aprendizagem, merece muito cuidado em análise e aplicação, posto que, se a generalização da definição e aplicação de língua estrangeira parece inadequada para esse séc. XXI, sua substituição soa ainda mais inadequada por oferecer uma "coloração" diferenciada para aqueles que buscam, consciente ou inconscientemente, uma higienização do adjetivo estrangeira. Tenho visto há algum tempo trabalhos sendo expostos em eventos e um conjunto de artigos e capítulos de livros nos quais seus autores - rotulando seu objeto como língua adicional - descrevem e analisam livros e materiais didáticos, gêneros produzidos por estudantes, diários reflexivos e portfólios, aulas e crenças de professores de PFOL ou PLNM, 
depoimentos de estrangeiros, ações de extensão em diversas cidades e diferentes contextos brasileiros. Por outro lado, a política linguística de institucionalização do português e do espanhol na UNILA (cf. CARVALHO, 2012a; 2012b), a partir de agosto de 2010, tem promovido tal concepção - incluindo os nomes dos componentes curriculares Português/Espanhol Adicional - para situações, complexidades e sujeitos que, a meu ver, são muito díspares.

Assim, a ideia de adição de [mais] uma nova língua ao repertório do sujeito pode conduzir ao equivocado entendimento de que uma língua não se constitui como entidade simbólica no processo histórico de construção de identidades, sujeita às relações de poder e à ordem dos discursos (FOUCAULT, 1996) e das instâncias político-jurídicas. Ao contrário, basta que se escolha uma dada língua, se a aprenda adicionando-a à $[\mathrm{s}]$ outra[s] que já carrega em sua "bagagem cultural" e assim se possa comunicar na internet, no trabalho, no dia a dia e nas esferas transnacionais posto que "essas línguas fazem parte dos recursos necessários para a cidadania contemporânea" (SCHLATTER; GARCEZ, 2009, p. 127128). Evidentemente, essa não é a compreensão de língua desses autores, posto que ambos vão ter um entendimento de que o português é uma língua no interior do repertório linguístico e cultural que os educandos já apresentam como forma de expressão na sociedade.

Ainda assim é preciso voltar atentamente à noção de LA tal como defendem seus usuários. A longa citação apresenta, pois, uma opção substitutiva (1), algumas justificativas da escolha (2), uma utilidade pragmática (3), uma operacionalidade (ou aplicaşão) (4) e um convite (5) à sua adoção:

Nos referimos aqui ao objeto de ensino da disciplina curricular "Língua Estrangeira" não como língua estrangeira, mas como [1] língua adicional. Essa escolha se justifica [2] contemporaneamente por diversas razões, a começar pela ênfase no acréscimo que a disciplina traz a quem se ocupa dela, em adição a outras línguas que o educando já tenha em seu repertório, particularmente a língua portuguesa. [...] Além disso, temos em conta que o espanhol e o inglês, as duas línguas adicionais oferecidas nas escolas da rede pública estadual, são de fato as duas principais línguas de comunicação transnacional [3], o que significa que muitas vezes estão a serviço da interlocução entre pessoas de diversas formações socioculturais e nacionalidades, de modo que é comum não ser possível identificar claramente nativos e estrangeiros. De fato, se consideramos que o espanhol e o inglês constituem patrimônios relevantes 
para a formação do cidadão a ponto de nos ocuparmos do seu cultivo na educação nacional, entendemos que, de alguma maneira, essas línguas fazem parte dos recursos necessários para a cidadania contemporânea [4]. Nesse sentido, são línguas adicionais, úteis e necessárias [3] entre nós, não necessariamente estrangeiras. Assim, falar de uma língua adicional em vez de língua estrangeira enfatiza o convite para que os educandos (e os educadores) usem essas formas de expressão para participar na sua própria sociedade [5]. Conforme discutimos a seguir, esse convite envolve também a reflexão sobre que língua é essa, de quem ela é e de quem pode ser a que ela serve o que cada um tem a ver com ela. (SCHLATTER; GARCEZ, 2009, p. 127-128; enumeração e grifos meus)

Ao analisarmos tal citação, podemos entender que a definição de língua adicional não está clara nesta argumentação a não ser como alternativa à de língua estrangeira (vista como obsoleta), que não mais atende ao tempo histórico contemporaneidade (ou neste século XXI?) ou para a cidadania contemporânea (época de sua proposição). Nesse sentido, tanto o inglês e o espanhol quanto o português como LNM, como objeto de ensino, seriam línguas adicionais, não como estrangeira, dado o fato de que agora estamos na era das línguas úteis e necessárias. Diante dessa nova concepção de língua, em que medida o português aprendido, adquirido e/ou falado nos diversos espaços enunciativos da UNILA em relação às demais línguas, se configura como [mais] uma língua? Para refletir sobre esta questão e sobre o contexto que venho descrevendo a partir de minha prática, cabe voltar a outros referenciais. Retorno então ao texto de Clarissa Menezes Jordão no domínio do ensino de inglês.

Jordão (2014) discute várias designações para o inglês, partindo de dois eixos orientadores: o da práxis pedagógica relacionada ao ensino-aprendizagem de inglês no Brasil em escolas públicas e o do referencial teórico pós-estruturalista (o da episteme) orientado pelas ideias foucaultianas e derridianas a respeito das concepções de texto e discurso. A autora situa a designação inglês como língua estrangeira como categoria central em contraposição a outras designações, considerando a história do seu uso no Brasil. Dentre suas análises, ela vai discutir a emergência das nomeações "inglês como língua adicional” (ILA) e "inglês como segunda língua" (ISL), enfocando a primeira. Ela justifica essa escolha por considerar que 
[...] ele [ILA] tem sido utilizado no Brasil mais recentemente em referência a situações de uso entre falantes de mais de uma língua, o que parece se dar com a dupla intenção de ressaltar o caráter plurilíngue das sociedades tidas como monolíngues, e de contemplar usos locais do inglês em países como o Brasil, mas é difícil afirmar tal leitura com segurança, pois ainda são poucos os textos que abordam mais a fundo a questão da preferência pela nomenclatura nos contextos brasileiros. (JORDÃO, 2014, p. 15)

A autora desenvolve uma discussão a partir de dados quantitativos levantados, em 2013, em portais e plataformas de publicações cientificas e eventos acadêmicos nas áreas de educação, linguística, linguística aplicada, avaliando a frequência dos termos língua estrangeira e língua adicional referente ao ensino de inglês no contexto brasileiro. Ela vai concluir que "o termo adicional é mais frequentemente usado em situação de "segunda língua" do que de "língua estrangeira", talvez menos por convicção do que pela sensação de atualização que o novo termo traz consigo.” (p. 29) Dessa leitura de Jordão (2014), embora a interpretação se volte especificamente para o caso do inglês no Brasil, podemos extrair três observações nada conclusivas, mas destacáveis: (a) há uma vontade de atualização e novidade para designar esse objeto (português para falantes de outras línguas); (b) há um crescente uso do termo nas mais diversas situações, incluindo aí o contexto de imersão, o que difere da situação do inglês no Brasil; (c) parece haver uma compreensão de que se vive em contexto plurilíngue, condição para que o português para falantes de outras línguas passe a ser mais uma entre aquelas que os aprendentes já trazem (seja materna; seja materna + uma segunda língua, uma terceira). O que colhemos dessa reflexão é um problema de análise que urge ser estudado no Brasil, considerando por contraste dois contextos de pesquisa: $\mathrm{o}$ do nível restrito (a práxis, objeto didático) centrado na situação da UNILA e o do nível ampliado (a episteme, objeto teórico) voltado aos usos da terminologia no discurso científico (no campo da linguística, da linguística aplicada e do ensino de PFOL/PLNM).

Flores (2013), por vez, vai apresentar uma reflexão sobre o Português Língua não Materna a partir de uma discussão mais ampla no interior da Linguística. Ela o situa na relação com outras noções que, muitas vezes, são tomadas como sinônimos ou, simples- 
mente, ignoradas por falta de compreensão sobre as especificidades que envolvem o sujeito, a família, a relação do uso e do funcionamento da língua com o falante, a questão das práticas de ensino etc., a exemplo do Português como Língua de Herança. A linguista coloca então o English as an Additional Language (EAL), ao lado de outras designações, como um tipo de noção específica relacionada ao tipo de falante e às distintas maneiras de adquirir/aprender a língua. Desde a introdução do artigo "Português Lingua Não Materna. Discutindo conceitos de uma perspectiva linguística", a autora já anuncia uma diferença entre o contexto português e o anglo-saxônico:

Português Língua Não Materna é um conceito abrangente, que inclui diferentes tipos de aquisição, de aprendizagem e de domínio da língua portuguesa. $\mathrm{O}$ uso deste conceito, de significado bastante amplo, é específico do contexto português. Não tem, por exemplo, equivalente no contexto anglo-saxónico, onde se diferencia entre conceitos como English as a Second Language (ESL), English as a Foreign Language (EFL) ou English as an Additional Language ( $E A L)$, sem que exista um termo mais vasto que abarque todos estes tipos de aquisição do inglês (*English as a non-native language). No entanto, devido a esta abrangência conceptual podemos estar a falar de falantes muito diferentes quando nos referimos a falantes de PLNM: ao português falado pelos filhos de emigrantes portugueses que residem ou regressaram de um país de emigração, ao português adquirido pelos filhos de imigrantes residentes em Portugal, ao português aprendido por falantes estrangeiros num curso de Português para Estrangeiros ou ao português falado, por exemplo, por estudantes timorenses que aprendem a língua portuguesa no momento da escolarização. (FLORES, 2013, p. 1)

No decorrer do trabalho, Flores (2013) apresenta uma discussão em torno das noções de PLH, L2 e PLE, pontuado as especificidades de cada uma, com ilustrações bem claras, e o que defendem os investigadores. Pode-se, dessa forma, concluir que as implicações para a definição de PLNM parecem longe de se permitir um consenso na comunidade de linguistas e investigadores hoje, carecendo de uma definição clara como concluiu a autora. Assim, o que me parece importante destacar é o fato de que é preciso levar em conta as diferentes experiências didáticas, teóricas e pedagógicas dos professores que têm trabalhado na área de ensino de PFOL e PLNM e, sobretudo, em contextos plurilíngues e integracionistas. No caso do português do Brasil, onde as pesquisas e as reflexões nessa área 
ainda são muito recentes, como bem discute Furtoso (2009), tais experiências devem se constituir como um elemento fundamental tanto para a definição do objeto (teórico, didático e semiótico) quanto para a formação de professores de PFOL, a melhora dos processos que envolvem o ensino-aprendizagem e a aquisição do português para aqueles que tiveram vivências linguísticas outras antes mesmo do português. Ou ainda: no caso dos falantes de português como LH, quando uma língua (ou mais de uma) passou a ter uma posição e um valor cultural, político e social que transcendem os espaços mais restritos de uso do português falado entre sua família e amigos familiares lusófonos.

\section{O perfil da turma: observações durante e construção de dados}

Descrevo a seguir as principais características de um grupo de estudantes de português na UNILA, levando em conta um questionário que distribuo nos primeiros encontros a fim de conhecer o perfil linguístico e sociocultural dos estudantes. Além disso, apresento o objetivo e a ementa do curso, além de alguns acontecimentos em que o aspecto intercultural e plurilíngue se impõe como uma quase constante no decorrer dos encontros. Os nomes do[a]s estudantes foram substituídos por seus gentilícios ou por termos da mesma sequência de letras de suas nacionalidades a fim de ocultar seus nomes civis e suas identidades legais.

Quadro 01 - Perfil diagnóstico da turma na primeira semana de aula (15 e 17/03/2017)

\begin{tabular}{|c|c|c|c|c|c|c|}
\hline UNILA & \multicolumn{6}{|c|}{$\begin{array}{l}\text { CURSO: CIÊNCIAS BIOLÓGICAS - } \\
\text { ECOLOGIA E BIODIVERSIDADE }\end{array}$} \\
\hline GER0040 & \multicolumn{2}{|c|}{$\begin{array}{l}\text { PORTUGUÊS LÍNGUA } \\
\text { ADICONAL BÁSICO (8 } \\
\text { CRÉD.) }\end{array}$} & \multicolumn{2}{|c|}{ SEMESTRE 2017.1} & $\begin{array}{c}\text { C.H./ } \\
\text { SEMANA } \\
8 \mathrm{~h} \\
\end{array}$ & $\begin{array}{l}\text { C.H. } \\
136 \mathrm{~h}\end{array}$ \\
\hline & & & & & & \\
\hline No. & IDENTIF. & PAÍS & GÊNERO & LM & LE & ACPort \\
\hline 01 & chilena & Chile & $\mathrm{F}$ & ESP & ING-1 & 0 \\
\hline 02 & cubano & Cuba & $\mathrm{M}$ & ESP & POR-2 & 2 \\
\hline 03 & peruana & \multirow{3}{*}{ Peru } & $\mathrm{F}$ & ESP & - & 0 \\
\hline 04 & peruano & & $\mathrm{M}$ & ESP - QUE & 2 & 1 \\
\hline 05 & peruan & & $\mathrm{M}$ & ESP & ING-2 & 1 \\
\hline 06 & paraguaia & \multirow{4}{*}{ Paraguai } & $\mathrm{F}$ & ESP - GUA & POR-1 & 1 \\
\hline 07 & paraguaio & & $\mathrm{M}$ & ESP - GUA & POR-2 & 2 \\
\hline 08 & paraguay & & M & ESP & & 0 \\
\hline 09 & parágua & & $\mathrm{F}$ & ESP - GUA & & 0 \\
\hline 10 & colombiano* & Colômbia & $\mathrm{M}$ & ESP & ING-1 & 0 \\
\hline
\end{tabular}




\begin{tabular}{|c|c|c|c|c|c|c|}
\hline 11 & colombian & & M & ESP & & 0 \\
\hline 12 & colombiana** & & F & ESP & ING-2 & 0 \\
\hline 13 & colombio*** & & $\bar{M}$ & ESP & ING-1 & 0 \\
\hline 14 & colombi & & $\mathrm{M}$ & ESP & & 0 \\
\hline 15 & colombia & & $\mathrm{F}$ & ESP & ING-2 & 1 \\
\hline & & & & & & \\
\hline $\begin{array}{c}15 \\
\text { alunos }\end{array}$ & $\begin{array}{l}6 \text { colombianos } \\
4 \text { paraguaios } \\
3 \text { peruanos } \\
1 \text { chilena } \\
1 \text { cubano }\end{array}$ & 5 Países & $\begin{array}{l}9 \text { Masc } \\
6 \text { Fem }\end{array}$ & $\begin{array}{l}\text { Faixa etária } \\
17 \text { a } 31 \text { anos }\end{array}$ & & \\
\hline LEG & \multicolumn{6}{|c|}{$\begin{array}{l}0=\text { nenhum; } 1 \text { = básico; } 2 \text { = intermediário } \\
\text { ACPort - algum conhecimento de português antes do curso } \\
* \text { estudante do curso de Química; } \\
\text { ** estudante de Biologia de uma universidade colombiana em mobilidade intercâmbio (1 se- } \\
\text { mestre); } \\
* * * \text { aluno com grau moderado de perda auditiva. }\end{array}$} \\
\hline
\end{tabular}

Fonte: Arquivo pessoal (RIBEIRO, 2017)

O quadro acima sintetiza o perfil de uma turma de Português como Língua não Materna (PLNM), cujo nome do componente curricular era GER0040 Português Adicional Básico, construído na primeira semana de aula (15 e 17 de março de 2017). O componente foi oferecido a 13 estudantes do curso de Ciências Biológicas - Ecologia e Biodiversidade, 1 estudante do curso de Química - Licenciatura e 1 estudante participante de programa de mobilidade intercâmbio (1 semestre) oriunda de curso de biologia de uma universidade colombiana. Desse grupo, desde o primeiro encontro, um aluno de origem colombiana sentava-se muito próximo da mesa do professor. Ele me pediu ao término da aula para falar mais alto, mais devagar, de forma mais articulada e olhando para ele quando fosse possível, pois sofria de perda auditiva do lado direito.

A disciplina era ministrada às quartas e sextas-feiras à tarde, com carga-horária de 8 horas semanais, totalizando 136 horas ao término do semestre. A disciplina tinha como ementa o "Reconbecimento da diversidade linguístico-cultural latino-americana e interação, oral e escrita, em situações cotidianas, sociais e acadêmicas." Além disso, durante o semestre, o professor tinha como objetivos norteadores pré-definidos no Plano de Ensino do curso:

Promover o reconhecimento e a valorização das variedades linguísticas (orais e escritas, regionais, de gênero, de idade etc.) e desenvolver a habilidade de transitar entre variedades; desenvolver as competências linguísticas (fonético-fonológicas, morfossintáticas, 
lexicais, semânticas, textual-discursivas) e interculturais para interação em situações cotidianas em contextos sociais e acadêmicos; desenvolver a compreensão de textos científicos. (Cf. UNILA, 2018, s.p., grifos meus)

Dos 15 estudantes regularmente matriculados, com faixa etária de 17 a 31 anos, 9 eram do gênero masculino e 6 do gênero feminino, 6 eram colombianos $(4 \mathrm{M}+2 \mathrm{~F}), 4$ paraguaios $(2 \mathrm{M}+2 \mathrm{~F}), 3$ peruanos $(2 \mathrm{M}+1 \mathrm{~F}), 1$ chilena e 1 cubano, constituindo um grupo de aprendentes oriundos de 5 países da América Latina, cuja língua oficial é o espanhol, havendo o guarani e o quéchua como línguas oficiais ameríndias e de resistência na condição de língua materna respectivamente no Paraguai e no Peru. Dos 3 estudantes do Peru, apenas um registrou na ficha de diagnóstico ter o quéchua como LM, enquanto um estudante - entre os 4 de origem paraguaia - disse não falar pero ${ }^{5}$ entender a língua guarani, deixando o espaço em branco. Os demais paraguaios registraram tê-la como língua materna e de uso recorrente entre seus familiares, às vezes mais que o espanhol nas relações mais íntimas e afetivas, no seio familiar e entre amigos de infância.

Esse dado me chamou a atenção, entre os paraguaios, no decorrer do semestre quando os 4 se vinculavam nos intervalos para contar na língua guarani algum acontecimento ou comentar algum fato ocorrido entre os colegas, posto que os demais colegas hispanofalantes e o professor não os entenderíamos. A situação de empoderamento e total liberdade de uso do guarani, pouco a pouco em sala de aula, se manifestava através do sentimento de orgulho que carregavam em traduzir oralmente palavras e expressões para sua língua, muitas vezes ensinando-nos "como se diz eso em guarani” ou "eso não se diz em

\footnotetext{
${ }^{5}$ Destaco aqui essa construção " não falo pero entiendo" fazendo alusão a um enunciado muito recorrente nas relações interculturais envolvendo línguas diferentes ou sujeitos de fora de uma comunidade de falante de uma suposta língua estigmatizada socialmente. Na Tríplice Fronteira e sobretudo na Cidade do Leste (Paraguai), é notório o trânsito linguístico e intercultural em que a língua guarani ora é a língua em uso recorrente nas relações interpessoais e mais afetivas, ora ela dá lugar ao espanhol e ao português no nível econômico, administrativo e oficial. A depender da situação e quem o interroga, ao ser interpelado se um dado falante fala guarani, é possível se ouvir como resposta "não falo, mas entendo" ou "entiendo, pero no bablo". Esse fenômeno foi estudado pela argentina Carolina Gandulfo, cuja pesquisa etnográfica com crianças guaranis gerou o livro "Entiendo pero no hablo El guaraní "acorrentinado" en una escuela rural: usos y significaciones". Nas palabras de Grandulfo (2007, p. 31): “[...7respecto a la situación lingüistica de los niños en la escuela, comenzamos a escuchar diferentes relatos de maestros que hablaban sobre la probibición de hablar el guarani en la escuela, y cómo sus padres no les habian permitido hablar en guaraní cuando eran niños en sus casas. Estas mismas personas, cuando les preguntábamos si hablaban guarani, decían "entiendo pero no bablo"."
} 
guarani" quando "eso [isso]" é um pronome de categoria vazia (com função dêitica) sem preenchimento na língua guarani porque tal objeto, substância, sentimento ou ideia não fazem parte da cosmologia dos povos originários. Por exemplo: era comum o estudante PARAGUAIO nos explicar que não havia palavra equivalente a tablet, smartphone ou cabo USB em guarani como tampouco havia em português e espanhol, eu acrescentava. Mas arepuca e arapuca, acrescentava PARAGUAIA, coexistem nas línguas espanhola e portuguesa (variante brasileira) bem como no guarani, a partir da qual as duas primeiras incorporaram o uso, havendo o sentido de armadilha ou instrumento de caça de animais comumente usado pelos povos originários.

Uma das ocasiões registradas como triunfo de eventos comuns no decorrer do curso, como aqueles que acabei de descrever, foi registrada por mim quando os 4 estudantes pediram para cantar em guarani. Nessa vivência linguística da aula, para além de um projeto pedagógico, observei que a relação entre o português, o espanhol e o guarani - para os estudantes paraguaios - dava-se de forma diferente dos demais estudantes, como se as três línguas assumissem, em suas vidas, funções e lugares de pertencimento diferentes porém complementares. Era como se houvesse o lugar da língua oficial do colonizador (o espanhol) que lhes cumpria um papel e dado valor simbólico; o lugar do português da Universidade, da cidade de Foz, da Fronteira, do comércio, das relações amistosas, civis ou convencionais com os brasileiros (professores e estudantes brasileiros), o português da aula de língua não materna e, finalmente, o lugar do guarani como a língua do afeto, do orgulho (e até da vergonha), do seu país, da outra margem do rio Paraná, sobretudo a língua que unia os quatro conterrâneos como efeito de poder e resistência. Certa vez a aluna PARAGUAIA se sentiu confortável para me confessar: "cuando estoy muy molesta con alguien, profe, no le insulto en español; lo hago en guaraní... porque guarani es más, más... no sé decir... !el insulto es más fuerte!, ?vos podés entender, profe?” Eu entendi cada palavra do espanhol, mas não entendia a semântica do que ficou silenciado, não porque me faltaram mais palavras, mas porque me faltavam o saber, o sabor e os sentidos na/da língua guarani. Ela não me falou em guarani porque sabia que eu nada sabia de guarani. Levei dias pensando nesse enunciado meio opaco e ao mesmo tempo pleno, que havia escutado com tamanha sinceridade e silêncio. 
Levei dias pensando na incompletude do "más, más..." da aluna. Não havia adjetivo que lhe desse sentido porque esse "más" era do espanhol, não do guarani; e, se me dissesse em guarani, ela sabia que não me faria sentido pela minha incompletude na língua-cultura que não era minha.

\section{Algumas observações no universo da prática}

\section{A) Observações sobre o exercício de reflexão do professor}

O trabalho com o ensino de PFOL e PLNM é uma atividade complexa que coloca o professor constantemente diante de uma série de desafios. Compilar estes desafios numa lista aqui seria um trabalho improdutivo, visto que cada grupo, cada contexto, cada professor e cada material didático produzem efeitos dos mais variados, bem como professor e estudante são afetados por eles diariamente. O que vou descrever aqui é um recorte muito sintetizado da minha experiência com um grupo de estudantes de cinco países recém-ingressados na Universidade no Instituto Latino-americano de Ciências da Vida e da Natureza (ILACVN) da UNILA.

Do primeiro ao último dia de aula das 18 semanas, refleti sobre minha prática compilando um conjunto de informações e acontecimentos no interior da sala de aula, materializados em forma de dados dos mais diversos. Tais documentos se constituíam como materialidades de natureza plurissemiótica (SANTOS, 2015), ou seja, fotografias, vídeos, fichas de exercícios, avaliações holísticas, fichas de avaliações de produção e compreensão audiovisual, tabelas de notas de exames parciais e final, tarefas de descrição linguísticogramatical, Elementos Provocadores ${ }^{6}$, tarefas do Caderno de Questões do Exame CELPEBRAS, resumos e outros gêneros produzidos em sala de aula ou em ambiente extraclasse, além de anotações e diário de registros.

\footnotetext{
${ }^{6}$ Elemento Provocador consiste em uma ficha/cartão de tamanho A4 para leitura de cerca de 1 minuto no momento da interação face a face do Exame CELPE-BRAS cujo objetivo é estimular a conversa entre entrevistador e entrevistado estrangeiro. Disponíveis em: <http://www.ufrgs.br/acervocelpebras/arquivos/elementos-provocadores-da-parte-oral >. Acesso em: 02 maio 2020.
} 
Posto isso, me era de costume distribuir um formulário de perfil sociocultural e linguístico com função diagnóstica e didática para as aulas seguintes. Nesse formulário, eu listava perguntas para levantar as seguintes informações: nome completo, idade, país de origem, cidade, nacionalidade/naturalidade, quantidade de membros da família, sexo, identidade de gênero, língua materna, escolaridade e/ou formação anterior, curso na UNILA, conhecimentos de outras línguas, primeiros contatos com a língua portuguesa e/ou estudos dessa língua anterior à chegada na Unila, que "nível” de conhecimento de português declaram ter etc. Além de poder levantar informações com intuito de dinamizar a participação e a interação de todos "quebrando o gelo" natural do primeiro encontro em sala de aula, tal documento de imediato possibilitava fazer uma avaliação holística sobre os diferentes graus de saberes a respeito da língua portuguesa, identificar habilidades orais e escritas a partir de perguntas e respostas breves - muito comuns naquelas primeiras semanas em situações em que a língua obedece a um ritual administrativo na secretaria acadêmica da Universidade mas também, na Polícia Federal ou nos bancos. Para as semanas seguintes, a mesma ficha me serviria para refletir sobre o que já sabiam da língua portuguesa, como a entendiam, quais eram suas impressões, como a escreviam a partir de questões pessoais, quais eram suas crenças e representações sobre a sua própria língua, outras línguas e a língua portuguesa. No final do semestre, esse tipo de diagnóstico me levaria novamente a refletir sobre o primeiro encontro e, consequentemente, o decorrer do curso: que tipo de crenças e atitudes eles registraram sobre as línguas (as maternas e o português), que imagens fiz deles e, do mesmo modo, que imagens eles puderam expressar naquela primeira semana. A questão que me fazia, finalmente, era: que professor fui eu ao longo de minha prática? Que lugares identitários ocupei no processo?

De modo geral, esse tipo de atitude tinha outros propósitos. Meu objetivo era compor um conjunto de dados para que eu pudesse, ao término do curso, refletir sobre esta experiência didático-pedagógica e tomar decisões mais adequadas no planejamento de um novo curso, na elaboração de material didático, na [re]definição de sequências didáticas e na condução das aulas para um perfil de grupo semelhante, ou até mesmo distinto daquela 
turma, mesmo sabendo que cada grupo se define pela natureza dos sujeitos que o compõem, sempre nas relações entre aprendentes de PLNM, entre estudantes e professores[as]. Minha postura de reflexão e análise desses registros deveria ocorrer sobretudo ao término do curso, não apenas durante as ações.

\section{B) Observações sobre o estranhamento linguístico-cultural}

Na UNILA, a primeira semana do ano letivo era reservada a Atividades de Recepção aos Calouros $^{7}$ (6 a 10 de março de 2017), cuja programação compunha uma série de ações de integração. Tais atividades se configuravam em formato de amostra de cursos, palestras e exposição de ações nas áreas de ensino, pesquisa e extensão, visitas aos três campi da Universidade e a diversos espaços, instituições e recursos naturais disponíveis na cidade e seu entorno (museus, áreas de preservação ambiental, Parque Tecnológico de Itaipu-Binacional, Usina Hidrelétrica de Itaipu etc.). Esta semana, como era de costume, se tornou um período de fundamental importância para a recepção e a integração de estudantes estrangeiros e brasileiros no contexto acadêmico e urbano da cidade de Foz do Iguaçu-PR. É o momento que defino como a semana de estranhamento linguístico-cultural, por uma série de questões postas em jogo. Para muitos destes estudantes, oriundos de países latino-americanos e caribenhos, é a sua primeira experiência de imersão linguística-cultural.

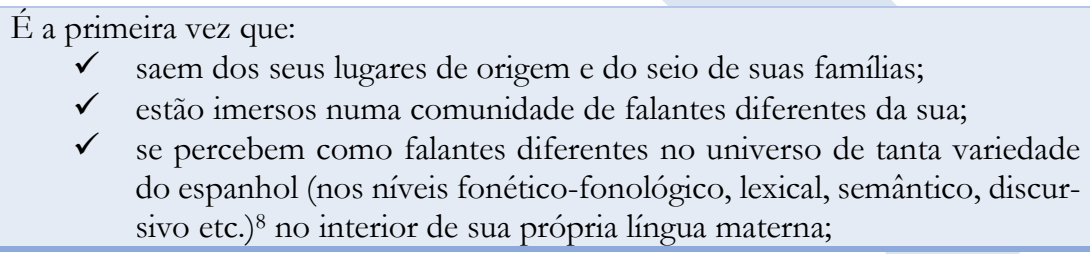

7 Disponível em: < https://portal.unila.edu.br/prograd/estudantes/calendario-academico/calendario-academico-2017>. Acesso em: 05 maio 2020.

${ }^{8}$ Embora não seja nosso objetivo analisar esse tema em específico, reconheço que a diversidade do espanhol e as implicações que surgem em sala de aula de PFOL, através dos falantes, afetam nossa prática quando os estudantes hispanofalantes abordam em aulas suas experiências, memórias, saberes e sentidos na/da sua língua na diferença com as variedades do espanhol em seus respectivos países. Normalmente esse tipo de questão comparativa se dá no âmbito lexical, prosódico etc. $\mathrm{Na}$ verdade, os estudantes passam a refletir sobre sua própria língua e suas identidades culturais, compreendendo as relações históricas entre suas identidades linguísticas ao passo em que 
$\checkmark$ têm que entender ou se fazer entendido no posto da Polícia Federal para regularizar documentação de estrangeiros;

$\checkmark$ precisam tratar de aluguéis ou outra questão administrativa corriqueira na vida de qualquer estudante;

$\checkmark$ se veem como não pertencidos, desterritorializados, diferentes, não entendidos etc.

Enfim, é a primeira de muitas vezes que o choque linguístico-cultural está intrinsecamente marcado pelo efeito da diferença, das muitas diferenças, que acaba[m] mudando a vida de estrangeiros e estrangeiras a começar pelo estranhamento da própria língua. Esse estranhamento é impactado na escuta da língua hegemônica de um país da dimensão do Brasil que muitos deles carregam no imaginário do futebol e do carnaval televisionado, mas só se dão conta na medida em que, através da semiologia da língua, vão se identificando consciente e inconscientemente com a semiologia da cultura, da história e da ciência construída e refletida no espaço da Tríplice Fronteira em particular. Vale ressaltar que a UNILA comporta professore[a]s e estudantes oriundos das mais diversas comunidades linguísticas brasileiras, nas quais a variedade do português apresenta características singulares. Esse aspecto não se restringe a apenas brasileiro[a]s, mas a indivíduos de diferentes nacionalidades que aprenderam e falam uma dada variedade do português em sala de aula com esses recém-chegados estrangeiros.

Ciente dessas observações que pontuei acima, o tema do estranhamento me interessa, portanto, não apenas em função das perguntas e das respostas que surgem em torno da "cultura brasileira" (sublinho aqui o problema homogeneizante dessa expressão), mas também a propósito das representações que fazemos (professor e alunos) das nossas culturas e das culturas do outro. Aprender português como língua não materna, nas condições

refletem o português que estão aprendendo. Por esta razão em particular, o professor deve estar muito ciente dessa especificidade para seu planejamento, regência e constante avaliação de seu exercício com esse grupo de sujeitos. Assim, a propósito do ensino de português para falantes de espanhol e do ensino de línguas próximas, ver trabalhos pioneiros como Costa (1995), Santos (1999), Carvalho (2002), entre outros pesquisadores que percorreram esse caminho de análise. Para uma abordagem discursiva, interculturalista e identitária a respeito dessas questões, como venho discutindo, ver Arnoux (2010), Mendes (2011) e Lima (2018). 
e situações em que os estudantes se apresentam na UNILA marcadas pelo pluralismo cultural e linguístico, punha em questão o lugar que ocupa o português na universidade, o lugar das demais línguas e a posição dos[as] professores[as] brasileiros[as] e estrangeiros[as] ${ }^{9}$ diante do espanhol e do português, considerando a natureza político-linguística de uma universidade internacional e integracionista. É exatamente aí que reside a importância de uma reflexão teórica cuidadosa, por parte do professor-pesquisador nas áreas de ensino de LE/L2, PFOL e PLNM, a partir da noção de representação e identidade para pensar o ensino de língua portuguesa num contexto como aquele que descrevi acima.

A concepção de representação, como discute Lima (2018) a partir de Silva (2000), desloca o conceito de identidade cultural hermética e estruturalista para dar lugar a uma nova compreensão de identidade pós-estruturalista, aquela definida pela natureza fluida e indeterminada da linguagem. A representação nessa perspectiva é um modo como atribuímos sentidos ao outro, à cultura e à história do outro, às nossas ações, saberes e conceitos que carregamos ou que, historicamente, contribuímos para a sua solidificação. Nesse viés, penso que os estudantes, ao entrar em contato com a língua portuguesa dentro e fora da sala de aula, nas primeiras semanas ou no decorrer do curso, trazem para as aulas os reflexos desse estranhamento imprescindível e inevitável que tornam fluidas nossas identidades. Assim, enquanto se questionam sobre o que entendem (ou não entendem) da nova língua, dos textos e da fala do professor, nós enquanto docentes devemos nos perguntar o que

\footnotetext{
${ }^{9}$ Sobre essa questão, refiro-me em particular aos professores dos diferentes institutos, centros interdisciplinares, cursos, disciplinas e áreas da UNILA, considerando as seguintes situações: 1) professores[as] de nacionalidade estrangeira que ministram seus cursos apenas em espanhol; 2) professores[as] estrangeiros[as] que ministram aulas apenas em português; 3) professores[as] estrangeiros[as] que ministram aulas nas duas línguas; 4) brasileiros[as] ou naturalizados[as] que ministram aulas apenas em português; 5) brasileiros[as] ou naturalizados[as] que ministram aulas nas duas línguas. Além desses perfis, há ainda os professores que ministram aulas de espanhol e português nos componentes curriculares PORTUGUÊS/ESPANHOL LÍNGUA ADICIONAL na língua objeto de estudo/prática no Ciclo Comum de Estudos (CCE). Até o momento, desconheço pesquisas que têm descrito e analisado estas situações tomando como sujeitos os docentes da Universidade e como problema em que língua [preferencialmente] ministram seus cursos. Há, no entanto, estudos voltados para a questão do bilinguismo nas áreas de ensino, pesquisa e extensão (OLIVEIRA, 2016; MOREIRA, OLIVEIRA, 2017) e representações de interação entre estudantes internacionais e corpo técnico administrativo (BIESDORF, 2020), ambos apontam para a complexidade das diferentes situações dos usos das línguas envolvendo professor, equipe técnica e estudantes.
} 
entendemos quando eles trazem seus saberes, suas histórias e [pre]conceitos, o que entendemos quando o silêncio preenche a lacuna entre a pergunta que lhes fazemos e os olhares desviantes, atentos ou indiferentes.

\section{Considerações finais para se reinventar}

No início desse artigo, deixei como uma ilustração a epígrafe com as palavras do educador e crítico cultural estadunidense Henry Giroux. Não fiz referência a suas palavras no decorrer de minhas reflexões não por acaso, mas para tentar dar um efeito de fechamento das lacunas que acabei evidenciando até aqui. Mas as lacunas funcionam também como possibilidades de abertura política constitutiva da linguagem na qual se produzem lutas. Em suas palavras, “[...] a linguagem deve ser compreendida tanto como uma política da representação quanto como uma prática social através da qual identidades são reconfiguradas, lutas são produzidas e esperanças mobilizadas". (GIROUX, 1995, p. 96) Assim, devemos encarar o trabalho com o ensino de PFOL e de PLNM, englobando as especificidades do ensino-aprendizagem do português dentro e fora do Brasil. Essa concepção de linguagem não exclui a língua de modo algum; ao contrário, traz a língua para uma compreensão política que nos define na diferença com o outro e, ao mesmo, nos aproxima do outro quando se ensina e se apr[e]ende uma língua-cultural.

Vale ainda sublinhar que a experiência e o desafio do ensino PFOL na UNILA me fez perceber alguns riscos na nomeação e na designação de uma língua quando os indivíduos envolvidos no processo de ensino têm relações muito diversas com a língua-cultura, ainda que sua língua materna (no caso dos hispanofalantes) venha a ser supostamente a mesma, uma língua próxima. O português é língua estrangeira para quem? É Língua Adicional em que circunstâncias? Essa designação serve a que propósito neste séc. XXI, nesse emblemático momento político porque passamos no Brasil e na UNILA? Enfim, que compreensão de língua e de ensino de línguas devemos assumir nesta nova década em que o conceito e a política de integração, entre nós latino-americanos, parecem tomar novos rumos, e o português do Brasil, infelizmente, vai se tornando uma língua tão estrangeira quanto 
aquela do século passado? É preciso contornar esse rumo produzindo lutas e mobilizando esperanças, como sugere Henry Giroux.

Quando as identidades são notavelmente diversas, o contexto como o que descrevi é plurilinguístico e intercultural, nós professores[as] nos descentralizamos na sala de aula para uma posição de escuta e observação, construindo um arquivo de estudo da nossa própria prática docente; há mais instabilidades no processo, porém, maior compreensão do nosso limite na ação de ensinar uma língua e aprender sobre o outro com infindável repertório de sentidos que os aprendentes trazem deles ou atribuem às palavras e aos textos que surgem e circulam em sala. Esse também é um problema de identidade e de representações reconfiguradas quando se produzem lutas, quando a gente se permite reinventar na própria prática de ensino e, como bem se descreveu a estudante francesa, quando se acredita que o[a] falante/aprendente de português vai mostrar quem é na ficção e "na vida real".

\section{ENSEÑANZA DE PORTUGUÉS A LOS HABLANTES DE OTRAS LENGUAS: IDEN- TIDADES Y [RE]INVENCIONES EN UN CONTEXTO DE INTEGRACIÓN}

RESUMEN: El propósito de este artículo es describir y analizar una experiencia didáctica con la enseñanza de portugués a estudiantes no brasileños en la UNILA, presentando los desafíos teóricos y didácticos en un contexto intercultural y plurilingüe. Para una mejor comprensión de estos análisis, me refiero exclusivamente a una clase de lengua (portugués - nivel básico) compuesta por 15 estudiantes hispanohablantes de cinco nacionalidades, en la que sintetizo algunos aspectos interculturales para pensar la cuestión de la identidad y de las representaciones en la enseñanza de portugués a hablantes de otras lenguas o como lengua no materna. Con este fin, analizo la relevancia de algunas designaciones, por ejemplo, lengua adicional para la especificidad del portugués enseñado y aprendido en el contexto de inmersión, transfronterizo y de integración por donde los sujetos transitan.

PALABRAS CLAVE: Enseñanza de PHOL; Identidad; Lengua-Cultura; Representaciones; UNILA.

\section{REFERÊNCIAS}

ALMEIDA FILHO, J. C. P. de. Dimensões comunicativas no ensino de línguas. Campinas-SP: Pontes, 1993.

ARNOUX, E. N. Representaciones sociolingüísticas y construcción de identidades colectivas en el Mercosur. In: CELADA, M. T.; FANJUL, A. P. ; NOTHSTEIN, S. Lenguas en un espacio de integración: acontecimientos, acciones, representaciones. Buenos Aires: Biblos, 2010. p. 17-38. 
BIESDORF, S. A. Representações das interações entre estudantes internacionais e corpo técnico-administrativo da UNILA: uma análise crítica. 140 f. 2020. Mestrado (Estudos Latino-Americanos) - Programa de Pós-Graduação Interdisciplinar em Estudos Latino-Americanos da Universidade Federal da Integração Latino-Americana. Foz do Iguaçu-PR, 2020.

BAKHTIN, M. Estética da criaģão verbal. Trad. Maria Ermantina Galvão G. Pereira. 2. ed. São Paulo, Martins Fontes, 1997.

CANALE, M., SWAIN, M. Theoretical bases of communicative approaches to second language teaching and testing. Applied Linguistics, v. 1, n. 1, p. 1-47, 1980.

CARVALHO, A. M. Português para falantes de espanhol: perspectiva de um campo de pesquisa. Revista Hispania, v. 85, n.3, p. 597-608, set., 2002. Disponível em: <http://www.jstor.org/stable/4141149?origin=JSTOR-pdf>. Acesso em: 30 abr. 2020.

- As relações de status entre as línguas na implementação em processo de uma proposta acadêmica bilíngue em uma cenário institucional multilíngue latino-americano. 2012a. 165 f. Dissertação (Mestrado em Letras) - Programa de Pós-Graduação em Letras, Universidade Federal do Rio Grande do Sul Porto Alegre, 2012.

CARVALHO, S. C. Política de promoção internacional da língua portuguesa: ações na América Latina. Trabalhos em Linguistica Aplicada. Campinas, n. 51, v.2, p. 459-484, jul./dez. 2012b.

COSTA, S. R. R. O ensino de português para estrangeiros em dimensão intercultural: rumo à expansão de adequada imagem do Brasil. In: ALMEIDA FILHO, J. C. P. de (org.). Português para estrangeiros: interface com o espanhol. Campinas: Pontes, 1995.

FLORES, C. M. M. Português como língua não materna. Discutindo conceitos de uma perspectiva linguística. In: BIZARRO, R.; MOREIRA, Ma.; FLORES, C. (Org.). Português lingua não materna: investigação e ensino. Lisboa: Lidel, 2013, p. 35-46.

FOUCAULT, M. O sujeito e o poder. In: DREYFUS, H.; RABINOW, P. (Ed.). Michel Foucault: uma trajetória filosófica para além do estruturalismo e da hermenêutica. Tradução V. P. Carrero. Rio de Janeiro: Forense Universitária, 1995. p. 231-249.

. A Ordem do Discurso. São Paulo: Loyola, 1996.

. Pouvoirs et stratégies (entretien avec Jacques Rancière, 1ère éd.,1977). In: Dits et écrits II: 1976-1988. Paris: Gallimard, 2001, p. 418-428.

FURTOSO, V. B. Aspecto da formação de professor de Português para Falantes de Outras Línguas. In - (Org.) Formação de professores de português para falantes de outras linguas: reflexões e contribuições. Londrina-PR: EDUEL, 2009, p. 23-40.

GIROUX, H. A. Praticando estudos culturais nas faculdades de educação. In: SILVA, T. $\mathrm{T}$ da (Org.). Alienigenas na sala de aula. Uma introdução aos estudos culturais em educação. Petrópolis: Vozes, 1995. p. 85-103. 
GANDULFO, C. Entiendo pero no bablo: el guaraní "acorrentinado" en una escuela rural: usos y significaciones. Buenos Aires: Antropofagia, 2007. Disponível em: <http://pdfhumanidades.com/sites/default/files/apuntes/Gandulfo\%2C\%20leer\%20cap $\% 201$ 3.pdf>. Acesso em: 05 abr. 2020.

HALL, S. Quem precisa de identidade? In: SILVA, Tomaz Tadeu da (Org.). Identidade e diferença: a perspectiva dos Estudos Culturais. Petrópolis-RJ: Vozes, 2000.

. Cultura e representação. Org. e revisão Téc. Arthur Ituassu; trad. Daniel Miranda e William Oliveira. Rio de Janeiro: Ed. PUC-Rio; Apicuri, 2016.

HYMES, D. On communicative competence. In: PRIDE, J. B., HOLMES, J. (Ed.). Sociolinguistics. Harmondsworth: Penguin, 1972. p. 269-293.

LIMA, L. M. Representaciones identitarias hispanohablantes: desarrollo de la competencia intercultural. In: MATOS, D.; PARAQUETT, M. (Org.). Interculturalidades: formação de professores de espanhol. Salvador-BA: EDUFBA, 2018, p. 101-119.

JORDÃO, C. M. ILA - ILF - ILE - ILG: Quem dá conta? RBLA. Belo Horizonte, v. 14, n. 1, p. 13-40, 2014.

MENDES, E. O português como língua de mediação cultural: por uma formação intercultural de professores e alunos de PLE. In: MENDES, E. (Org.). Diálogos interculturais: ensino e formação em português língua estrangeira. Campinas: Pontes, 2011. p. 139-158.

MENDES, E. A ideia de cultura e sua atualidade para o ensino-aprendizagem de LE/L2. Revista Entre Linguas, Araraquara, v.1, n.2, p. 203-221, jul./dez. 2015. Disponível em: $<$ https://periodicos.fclar.unesp. br/entrelinguas/article/view/8060/5489>. Acesso em: 25 mar. 2020.

MOREIRA, M. M., OLIVEIRA, B. M. O bilinguismo nas práticas de ensino, pesquisa e extensão da UNILA: um diagnóstico, em números, de sua realidade linguística. RELACult-Revista Latino-Americana de Estudos em Cultura e Sociedade, v. 03, dez., 2017. p. 1-12.

MOROTTA, T. Hablas português: estrangeiros contam como é aprender o idioma. In: Jornal Gazeta do Povo, Curitiba, 18 de abril de 2014. Disponível em : <https://www.gazetadopovo.com.br/vida-e-cidadania/hablas-portugues-estrangeiros-contam-como-e-aprender-o-idioma-e6ru6h2s8o4w17sat7pluaa1a/>. Acesso em: 05 abr. 2020.

OLIVEIRA, B. M. Las políticas de gestión de las lenguas en UNILA: un estudio de caso a partir de los documentos oficiales de la institución. In: Tercer CIPLOM/EAPLOM. Florianópolis, 2016.

SANTOS, P. O ensino de português como segunda língua para falantes de espanhol: teoria e prática. In: CUNHA, M. J.; SANTOS, P. (Org.). Ensino e pesquisa em português para estrangeiros: programa de ensino e pesquisa em português para falantes de outras línguas. Brasília: UnB, 1999. p. 49-57. 
SANTOS, J. R. Arqueologia da imagem no ensino de língua portuguesa: para uma história da imageria no ensino. 269 f. 2015. Tese (Doutorado em Linguística ) - Programa de Pós-Graduação em Linguística, Universidade Federal de São Carlos, São Carlos-SP, 2015.

SEVERO, C. G. Política(s) linguística(s) e questões de poder. Revista Alfa, São Paulo, n. 57, v.2, p. 451-473, 2013. Disponível em: <https://www.scielo.br/pdf/alfa/v57n2 /06.pdf>. Acesso em: 09 mar. 2020.

SILVA, T. T. da. A produção social da identidade e da diferença. In: SILVA, Tomaz Tadeu da (Org.). Identidade e diferença: a perspectiva dos estudos culturais. Petrópolis-RJ: Vozes, 2000. p. 73-102.

UNILA-Universidade Federal da Integração Latino-Americana. Projeto Pedagógico do Curso de Graduação: bacharelado em Ciências Biológicas - ecologia e biodiversidade. (Projeto Pedagógico aprovado pela Resolução CONSUN n ${ }^{\circ}$ 025/2013 e alterado pela Resolução COSUEN n ${ }^{\circ}$ 15/2018.). 2018. Disponível em: <https://unila.edu.br/sites/default/files/files/ProGrad/PPCs/PPC\%20Ciencias\%20Biologicas.pdf>. Acesso em: 20 mar. 2020.

WINDOWSON, H. G. Teaching Language as Communication. Oxford: Oxford University Press, 1978.

Recebido em: 23/05/2020.

Aprovado em: 12/06/2020. 